\title{
REDUCING AIR RESISTANCE ACTING ON A SHIP BY USING INTERACTION EFFECTS BETWEEN THE HULL AND ACCOMMODATION
}

\author{
Ngo Van He${ }^{1}$, Keisuke Mizutani ${ }^{2}$, and Yoshiho Ikeda ${ }^{3}$ \\ ${ }^{1}$ School of Transportation Engineering, Hanoi University of Science and Technology, Hanoi, Vietnam, \\ Tel : +84-4-3869-2501, Fax : +84-4-3623-0592, e-mail : he.ngovan@hust.edu.vn \\ ${ }^{2}$ Sanoyas Shipbuilding Corporation, Osaka, Osaka, Japan, Tel: +81-72-254-9343, Fax: +84-72-254-9914, \\ e-mail: k-mizutani@sanoyas.co.jp \\ ${ }^{3}$ Osaka Prefecture University, Osaka, Japan, Tel: +81-72-254-9343, Fax:+84-72-254-9914, \\ e-mail: ikeda@marine.osakafu-u.ac.jp
}

Received Date: December 26, 2014

\begin{abstract}
Nowaday, a study on saving energy as well as reducing resistance acting on a ship is important in maritime transportation. In this study, the authors present a study on reducing air resistance acting on a ship by using interaction effects between the hull and an accommodation. At first, air resistances acting on a hull and an accommodation of the ship are investigated by a commercial Computation Fluid Dynamic (CFD) code. Then, CFD results are compared with those of experimental results to validate the accuracy of the CFD. Secondly, air resistances acting on the ship with an accommodation on its deck are computed to obtain air resistances acting on the whole ships, on the hull and on accommodation. The results demonstrate that the interaction effects between the hull and its accommodation house be also shown how to reduce the total air resistance by using interaction effects between the hull and an accommodation house. The results can be applied in reducing the total resistances acting on a ship.
\end{abstract}

Keywords: Accommodation house, Air resistance, CFD, Hull, Interaction effects, Saving energy

\section{Introduction}

In previous papers, K. Matumoto et al. (2003) and Y. Nihei et al. (2008) studied on how to keep a ship as Pure Care Carrier (PCC) safety in strong wind at the ballast condition and how reduced resistance acting on the original ship [1, 2]. The authors proposed a new hull over water surface and reported that the total resistance acting on the new ship could reduce about $15 \%$ at wind speed $14 \mathrm{~m} / \mathrm{s}$ and $22 \%$ at wind speed $10 \mathrm{~m} / \mathrm{s}$. A study on the influent of wind is very important to consider the effect of wind on ship motion to avoid risks of collision and grounding. In other study, presented by T. Fujiwara et al. (2009) [3], the author study on experimental investigation and estimation on wind force for a container ship. By experiment, the aerodynamic characteristics on many types of external forms of the container ships had investigated at the wind tunnel with a $1.5 \mathrm{~m}$ block model. They proposed a new method $\theta$ f for estimating wind force coefficients of container ships. In other study presented by K. Sugata et al. (2010) [4], the authors focus on reduction of wind force acting on a proposed non ballast ship. The conclusion of the paper reported that a new type model of the non ballast ship which could reduce by $44 \%$ of wind force in full loaded condition, by $33 \%$ of wind force in the non ballast condition. 
In previous papers [5], which published by K. Mizutani et al. (2013), the authors presented a study on reduction of air resistance acting on a hull of the chip carrier by using a commercial Computation Fluid Dynamic (CFD) code “ANSYS-Fluent”. The authors proposed a new accommodation and hull for the ship. The CFD results showed that air resistance on air resistance between hull and accommodation of the ship can be reduced by interaction effects. Measurements of air resistance acting on the ship were carried out in towing tank of Osaka Prefecture University (OPU) to show that the proposed new hull and new accommodation could reduce from $2 \%$ to $15 \%$ of the total air resistance follows as wind direction from 0 to 180 degree. And, the CFD results were agreement with those of the experimental one. In other paper, N.V. He et al. (2013) [6], the authors proposed an optimum accommodation made of only flat plates, which reduces air resistance drastically, interaction effects on air resistance between hull and accommodation were significantly reduced. In the paper, K. Mizutani et al. (2014) [7], the author studied on Effects of cargo handling equipment on wind resistance acting on a wood chip carrier by using both CFD simulation and experiment investigated at the towing tank. The conclusion of the paper reported that improved ship could reduce by $10 \%$ of total air resistance. And, the CFD results were also in good agreement with the experimental data. In this paper, interaction effects of a hull and an accommodation on air resistance is investigated more in detail to find the way to reduce air resistance acting on a ship by using interaction effects between hull and accommodation on its deck.

\section{Accuracy of CFD results}

\section{Models and experimental setup}

In this section, air resistance acting on a chip carrier is determined experimentally. The CFD results are compared with those of the experimental one to validate the CFD results. Figure 1 shows a model of a ship used for the validation. Principal particulars of model are shown in Table 1, [7].

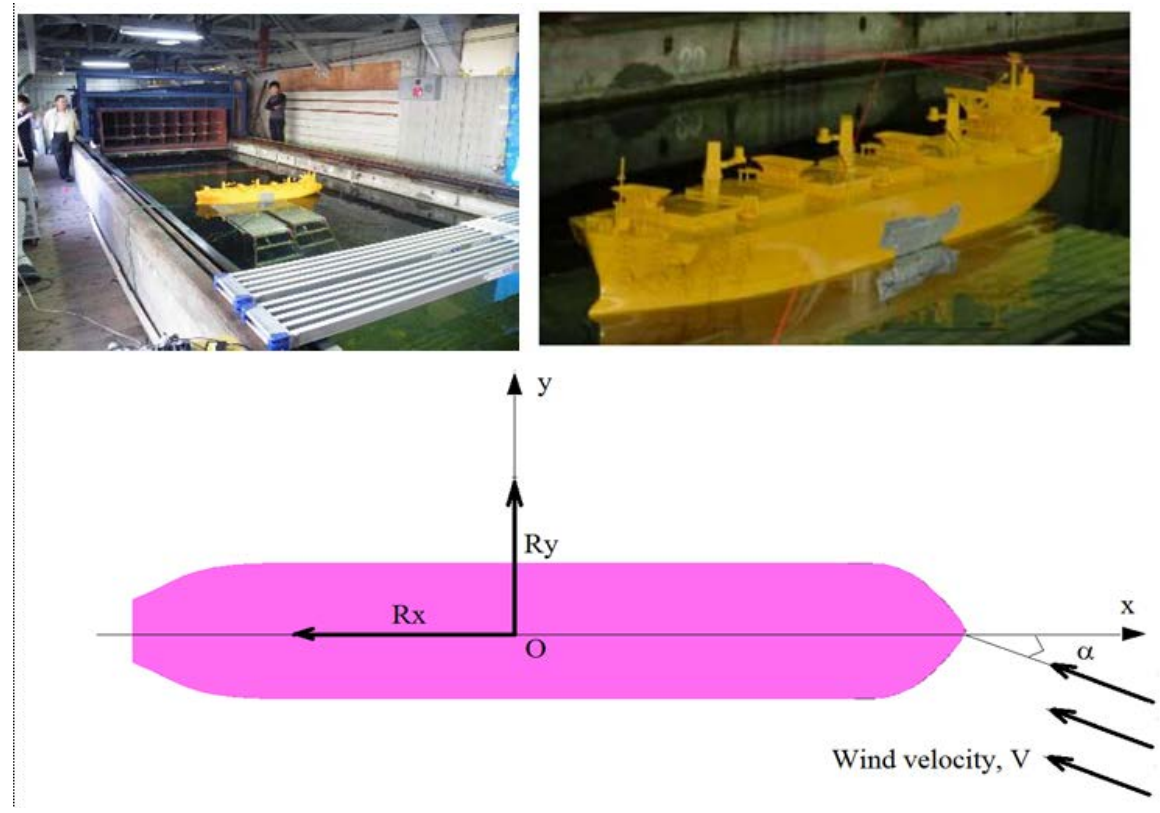

Figure 1. Experimental views and coordinate system 
Table 1. Principal Particulars of Ship Model

\begin{tabular}{ccc}
\hline Name & Model & Unit \\
\hline Length, $\mathrm{L}$ & 1.60 & $\mathrm{~m}$ \\
Breadth, B & 0.282 & $\mathrm{~m}$ \\
Depth, H & 0.171 & $\mathrm{~m}$ \\
Draft, d & 0.0485 & $\mathrm{~m}$ \\
Block coefficient, $\mathrm{Cb}_{\mathrm{b}}$ & 0.774 & - \\
Wind velocity, V & 14.50 & $\mathrm{~m} / \mathrm{s}$ \\
Wind attack angle & $0-180$ & degree \\
\hline
\end{tabular}

\section{Computation domain, meshing and boundary condition for CFD simulation}

In CFD simulation, computational fluid domain, meshing and boundary condition setup can affect the simulation results. In this study, all of step for designed simulated fluid domain, meshing and set the boundary condition has done follows as International Towing Tank Conference (ITTC) used guider for using CFD [8] and many experience in application CFD of the authors [9]. For a ship model of $1.6 \mathrm{~m}$ of length the calculated fluid domain is limited in $15 \mathrm{~m}$ of length, $3.6 \mathrm{~m}$ of breadth and $1.2 \mathrm{~m}$ of height. Meshing of the calculated fluid domain in unstructured mesh is generated in 3.8 million T-grids. For the CFD simulation, the turbulent viscous model $k-\varepsilon$ for unsteady flow is used. The pressure inlet is setup at the inlet, the pressure outlet is setup at the outlet of the calculating domain. Figure 2 shows the fluid domain for calculations.

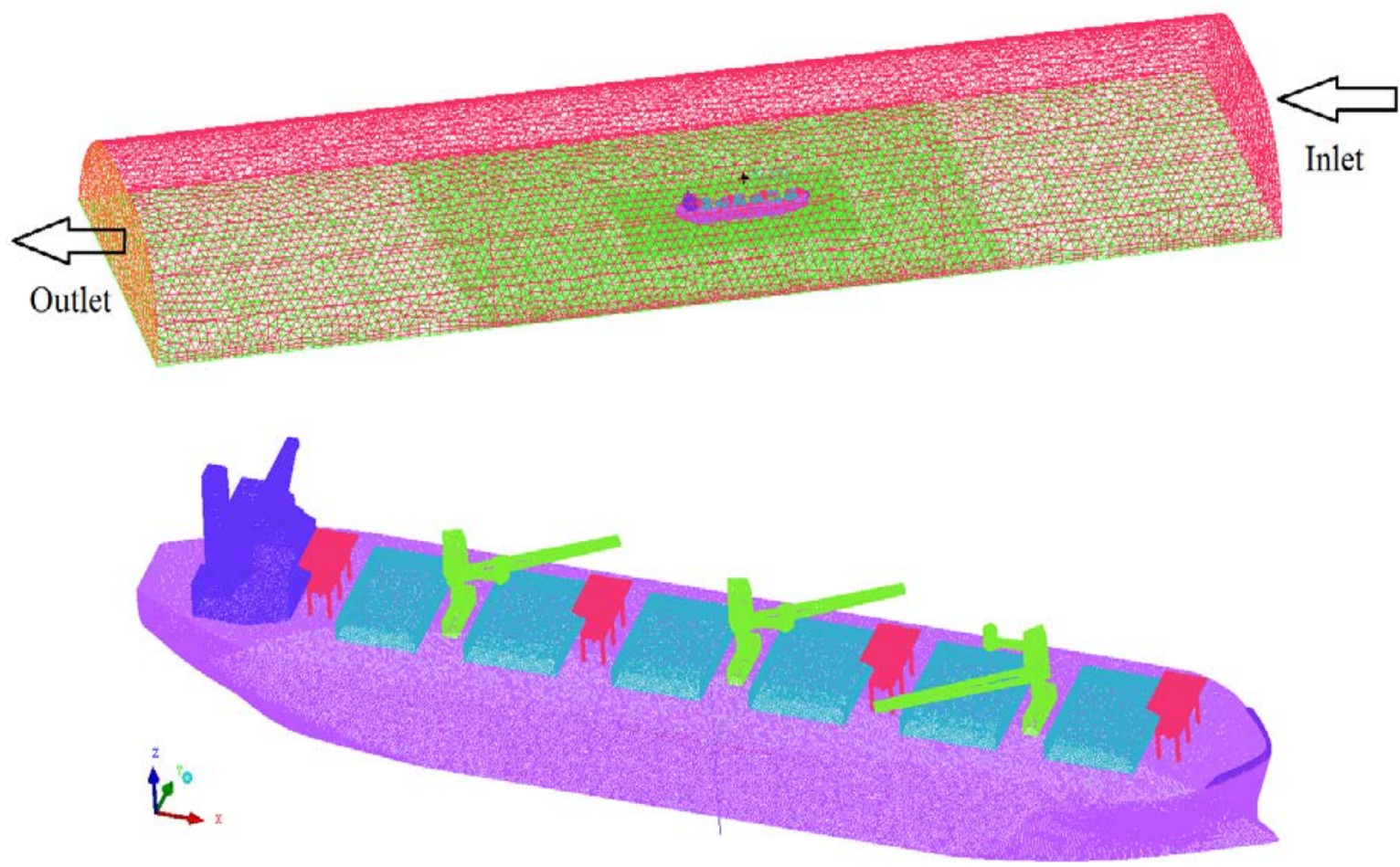

Figure 2. Computational fluid domain and meshing 


\section{Validation of CFD results}

For validation of CFD results, results of air resistance acting on the ship are compared with those of the experimental data. The experiments are carried out at a towing tank of Osaka Prefecture University in Japan [5, 7]. Figure 3 shows a comparison between the CFD results and the experimental data of ship in air resistances acting on the ship. The blue line shows the coefficient of air resistance acting on the ship given by the CFD, $C_{x}$ corresponding to wind attack angle, (Figure 1). The red dots show the experimental data. Agreement between them is fairly good as can be seen in the figure.

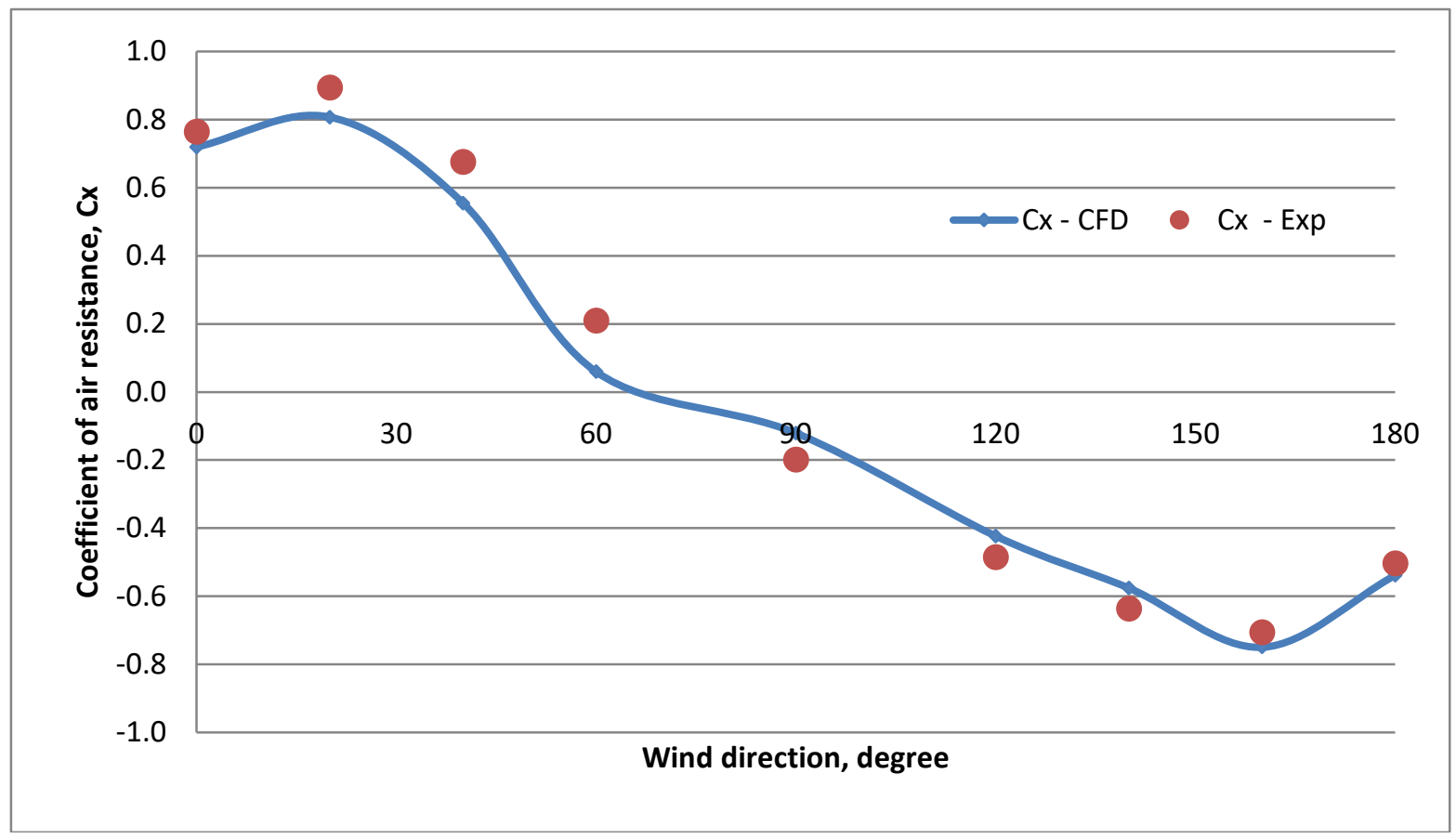

Figure 3. Comparison between CFD and experimental data

\section{Interaction effects between a hull and an accommodation house on air resistance acting on the ship}

\section{Air resistance acting on accommodation}

In this section, air resistances acting on several types of accommodations of a ship are calculated by using the CFD. The first type accommodation named as Box, has cube shape. The dimensions of Box were taken from the accommodation of the Chip Carrier as shown in Figure 1. The second kind of shapes, M1 and M2 are optimized box shapes accommodation which contain only plat plates. And new streamlined accommodation is proposed. These accommodations M1, M2 were developed in our previous paper N.V. He et al. (2013) [6]. All kinds have the same floor area. The shapes of the accommodation and their frontal projected area $\mathrm{S}_{\mathrm{FPA}}$ are shown in Figure 4. 


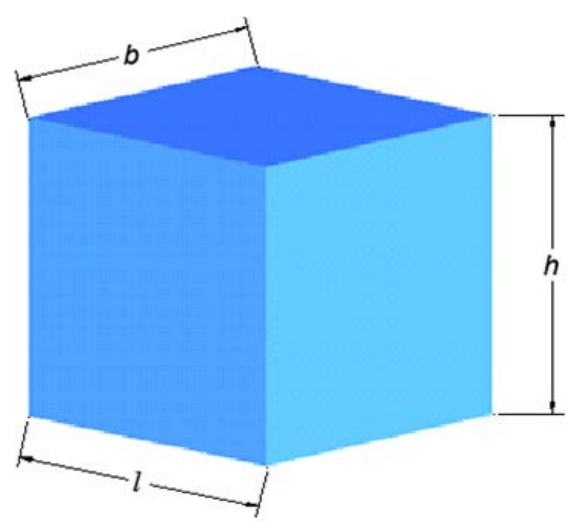

Box, $\left(\mathrm{S}_{\mathrm{FPA}}=0.016 \mathrm{~m}^{2}\right)$

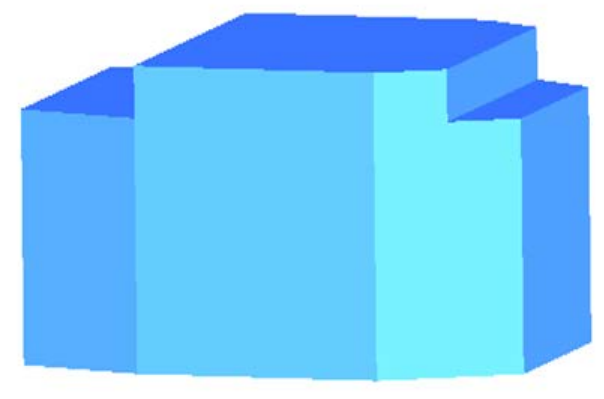

$\mathrm{M} 2,\left(\mathrm{~S}_{\mathrm{FPA}}=0.011 \mathrm{~m}^{2}\right)$

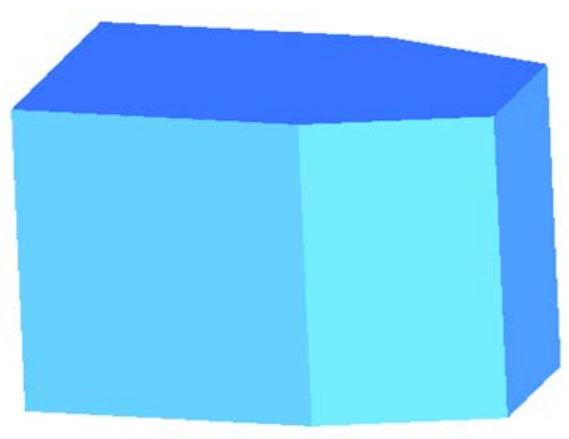

$\mathrm{M} 1,\left(\mathrm{~S}_{\mathrm{FPA}}=0.011 \mathrm{~m}^{2}\right)$

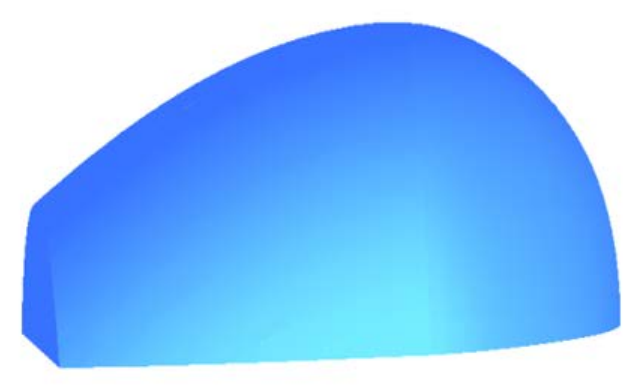

Streamline, $\left(\mathrm{S}_{\mathrm{FPA}}=0.015 \mathrm{~m}^{2}\right)$

Figure 4. Shape and frontal projected area of the accommodation house

Table 2 shows the computational result of air resistance acting on the original box shape accommodation and experimental data measured in the towing tank at Osaka Prefecture University. The wind velocity is set at $14.5 \mathrm{~m} / \mathrm{s}$ and wind direction 0 degree. The calculated result of the drag coefficient $C_{d}$ for the accommodation Box is almost 1 and is in good agreement with the experimental results.

Table 2. A Comparison of Air Resistance Between CFD and Experimental Results

\begin{tabular}{cccc}
\hline Name & $\begin{array}{c}\text { Coefficient of air } \\
\text { resistance, CFD }\end{array}$ & $\begin{array}{c}\text { Experimental } \\
\text { result }\end{array}$ & $\begin{array}{c}\text { Difference } \\
\%\end{array}$ \\
\hline Box & 1.07 & 1.09 & -2 \\
\hline
\end{tabular}

Figures 5 and 6 show computational results of dynamic pressure distribution at center plane and horizontal plane of computational fluid domain. In the figure, the blue area region indicate shows low dynamic pressure where static pressure is high. Red area region indicates high dynamic pressure and low static pressure. The region with high static pressure attached on the accommodation will strengthen air resistance. In the results, clearly differences among dynamic pressure distribution around accommodation can be seen. Low dynamic pressure area behind the streamlined accommodation is drastically reduced because of flow separation become small. 

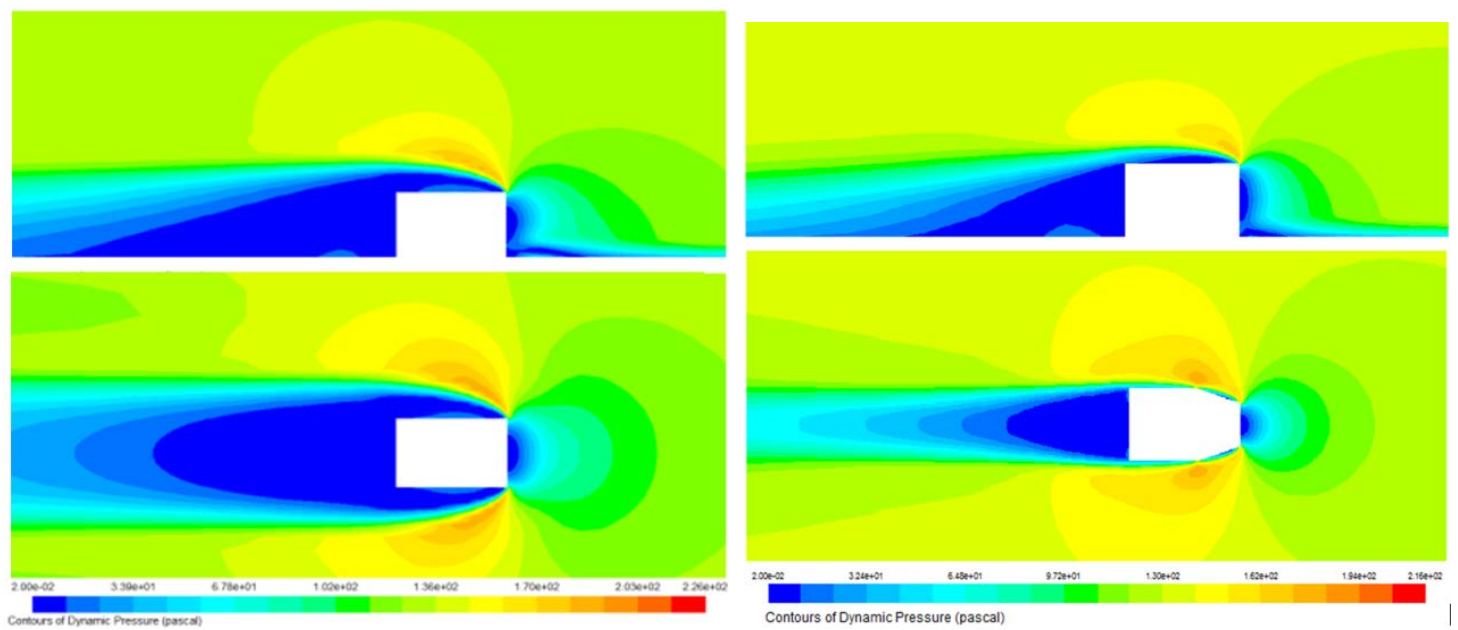

Figure 5. Dynamic pressure around Box shape, M1 (upper: side view, lower: top view)
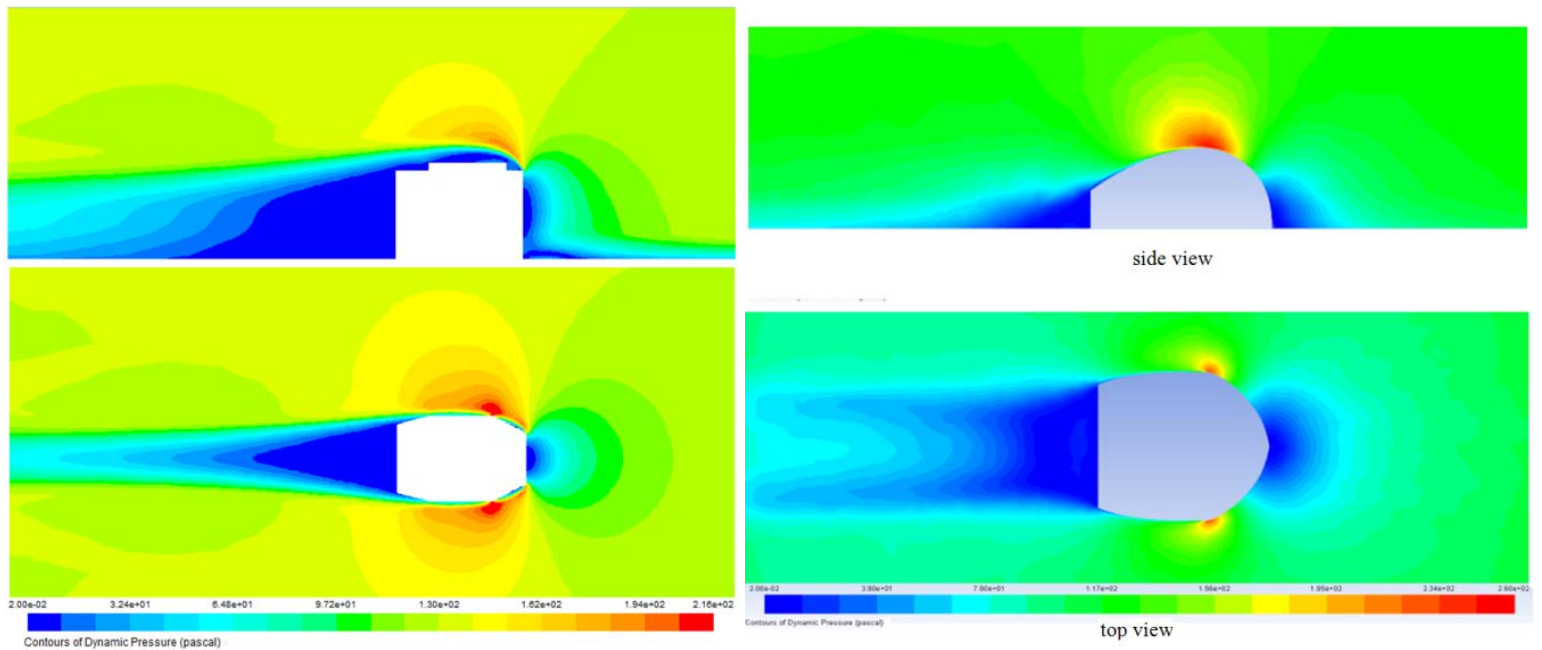

side view

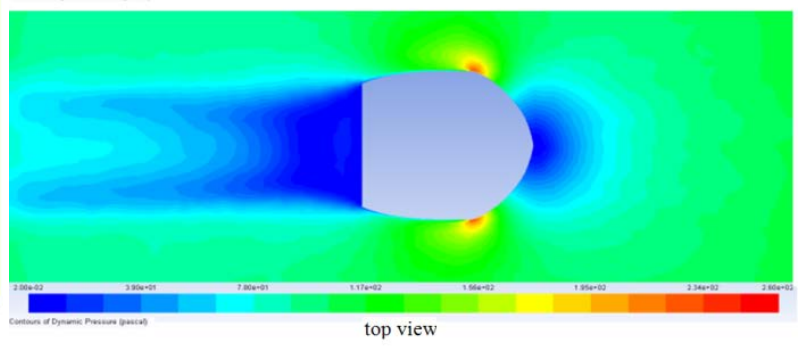

Figure 6. Dynamic pressure around M2 and Streamline (upper: side view, lower: top view)

In common of the effects on hydrodynamic force by shape, we can see that the streamlined shape is the best one in reduction of air draft. However, in the industrial ship building, it takes a high cost to manufacture a streamlined accommodation house. Therefore, an accommodation which made of only plat plates and optimum resistance is the best chosen for a ship building.

Figure 7 shows the air resistance acting on each accommodation. Drastically reductions of air resistance by the developed accommodations, M1, M2 and Streamlined accommodation can be seen. We can see that $72 \%$ reduction can be achieved for the streamlined one, but large reductions can be also obtained for simple shapes made from flat plates, M1 and M2. These results of drag forces are in agreement with the results of dynamic pressure as shown in Figures 5 and 6. 


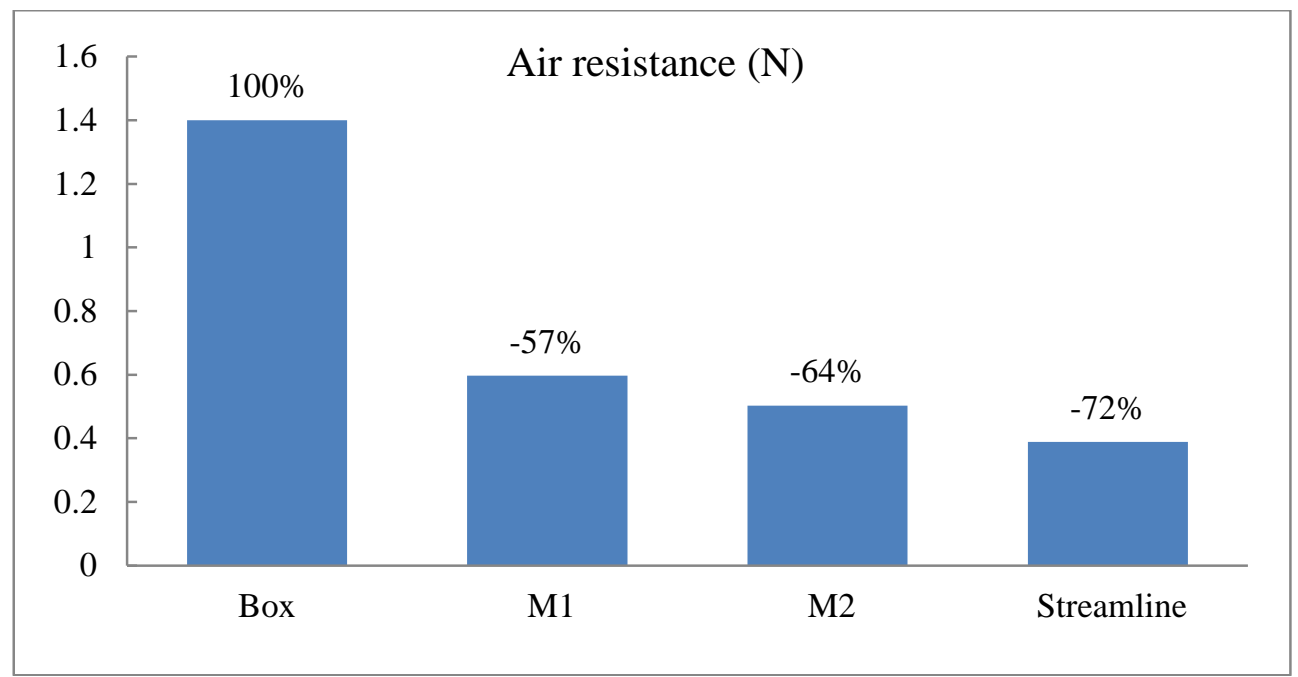

Figure 7. Air resistance acting on independent accommodation on hull

\section{Air resistance acting on a hull with a box-type accommodation house on deck}

In this section, air resistance acting on the ship hull with an accommodation on its deck is investigated. The hull of the chip carrier with a box shape accommodation on the deck is used in the studied. The shape of the accommodation is shown in Figure 8. To find optimum position of accommodation on deck, position of the accommodation is changing form aft to fore of the ship, and comparisons of the calculated air resistances are carried out to find the best one. Figure 9 shows the position of the box shape accommodation on the deck of the ship. Following locations of the accommodation on deck, models are named as well as from P1 to P11, N.V. He. et al (2013) [6], [9]. Figures 10, 11 and 12 show examples of dynamic pressure distributions at centre plane of the ship with the accommodation located at aft, mid and fore decks of the ship.
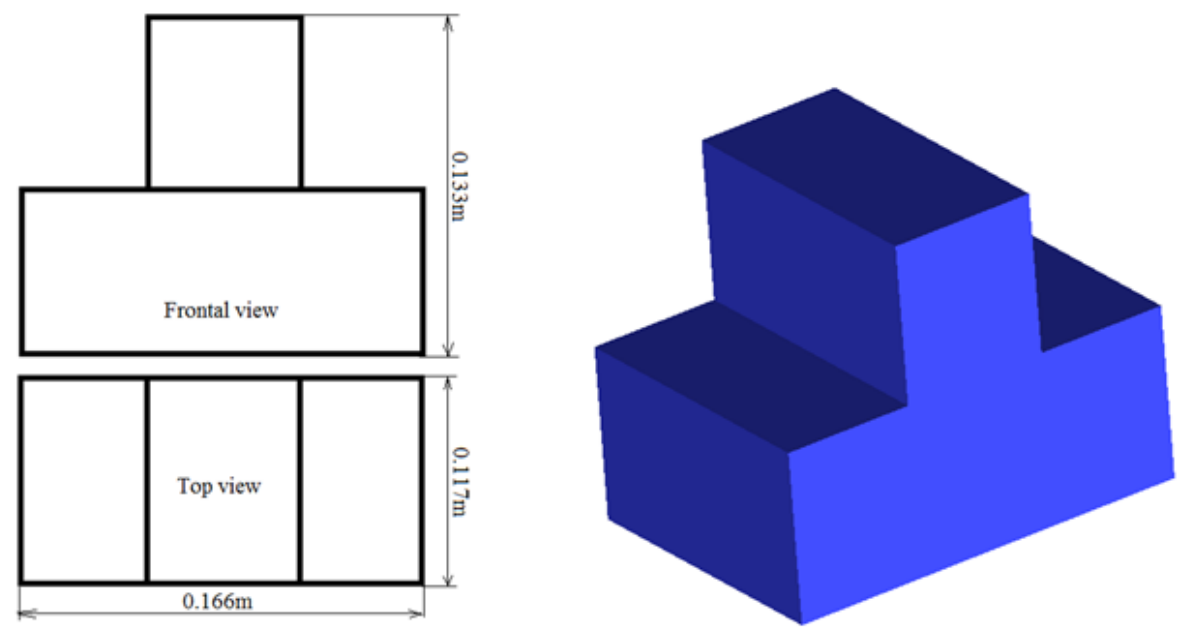

Figure 8. Box shape accommodation P1 to P11 


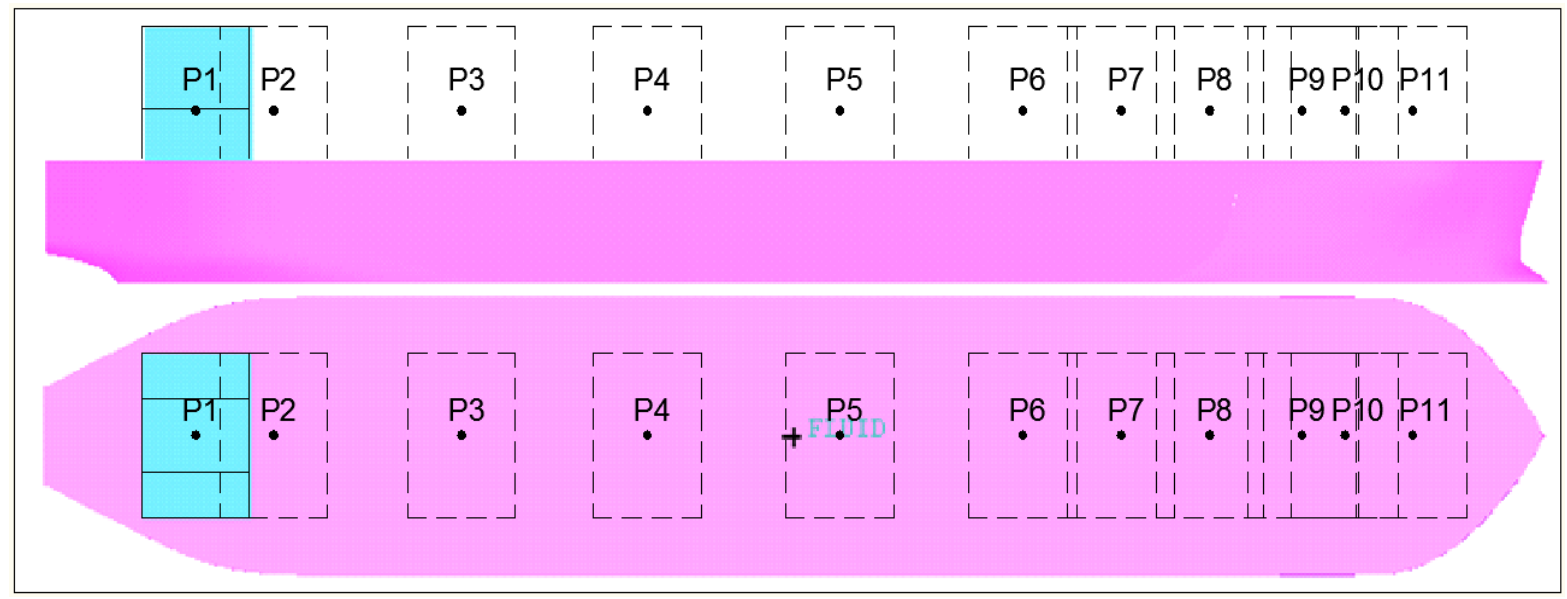

Figure 9. Location of accommodation on deck, P1 to P11

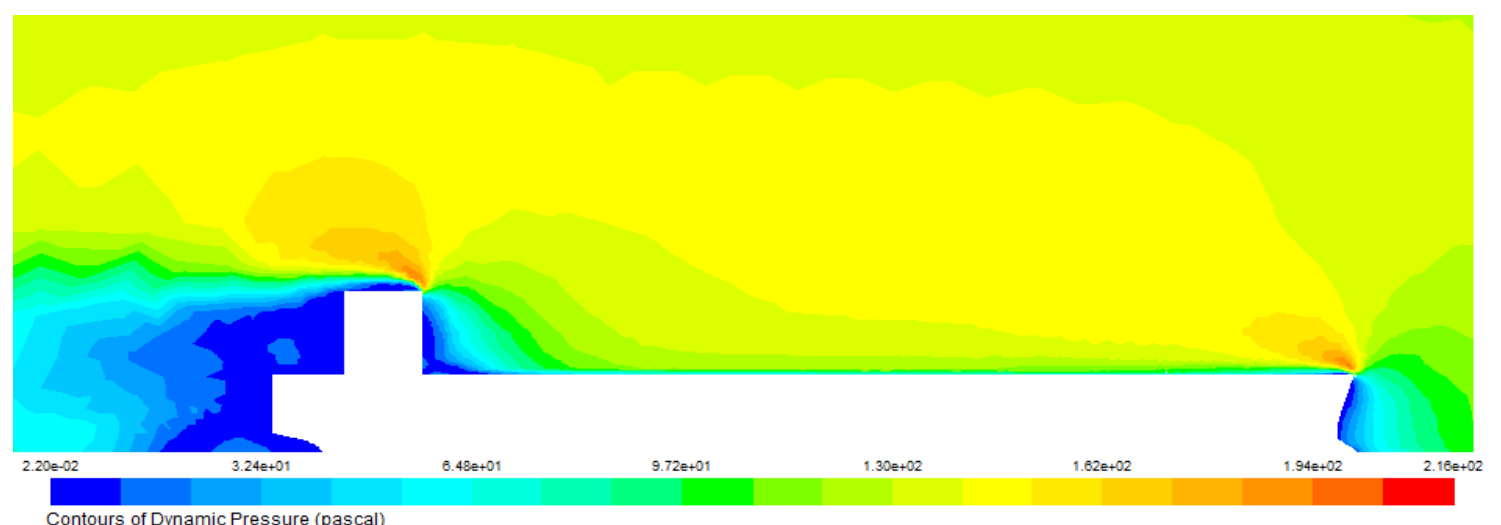

Figure 10. Dynamic pressure distribution at centre plan of calculating domain, P1

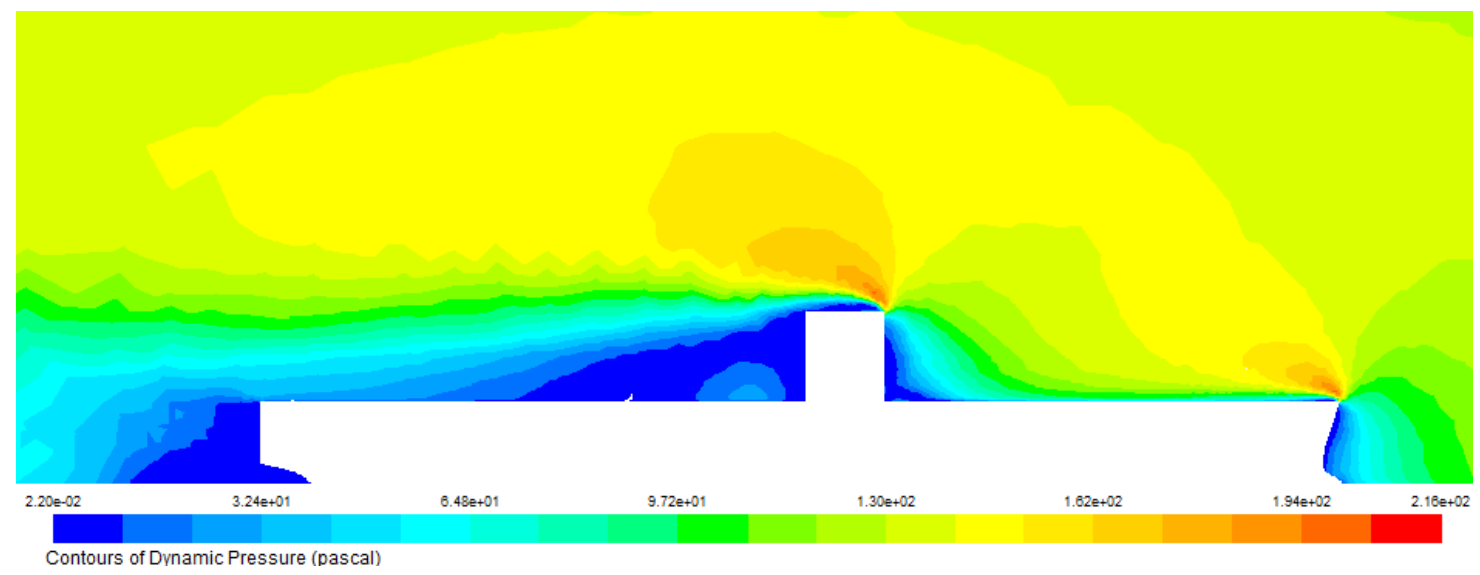

Figure 11. Dynamic pressure distribution at centre plan of calculating domain, P5 


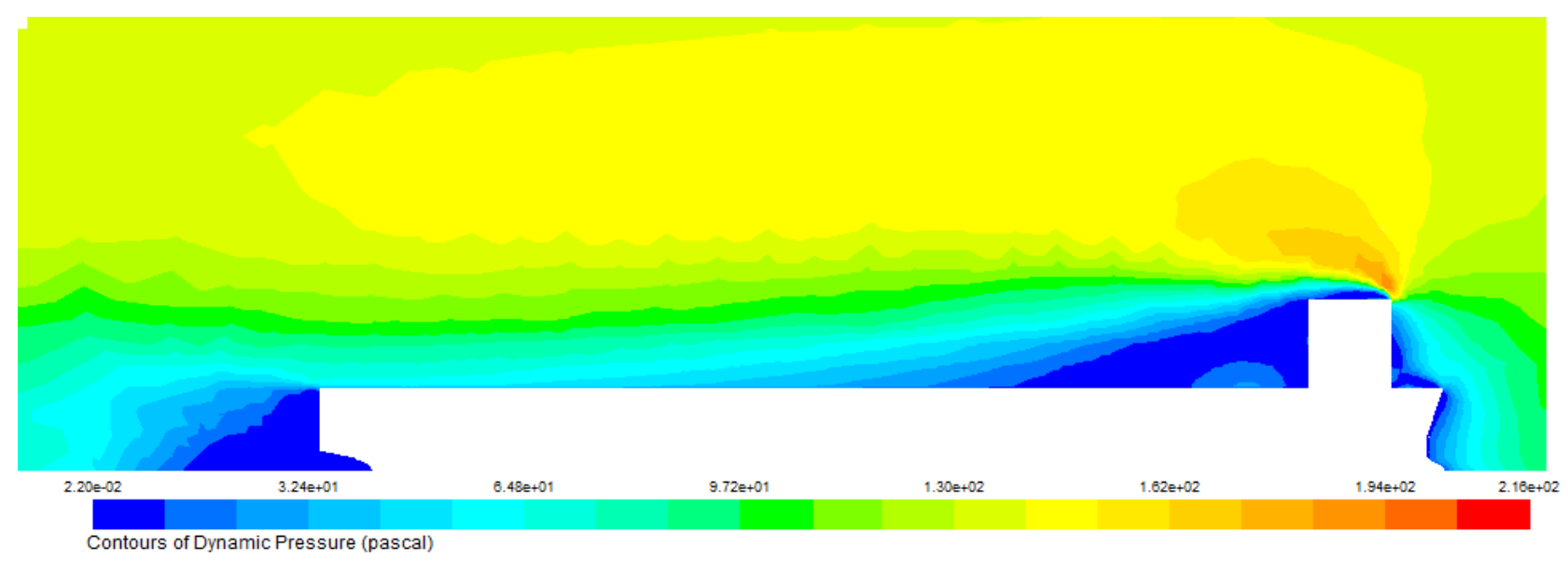

Figure12. Dynamic pressure distribution at centre plan of calculating domain, P11

Table 3 shows the computational air resistance acting on the ship according as position of accommodation on deck, from P1 to P11. The results as shown in the table demonstrate that the air resistance is smaller when accommodation which is located at the fore of the ship.

Table 4 shows the calculated results of interaction effect on the air resistance between the hull and the accommodation on deck. The interactions effects are comparing by subtract the air resistance on a whole ship, or an accommodation from the sum of the resistances acting on the independent hull and accommodation. The results demonstrate that the interaction effect cause increases in air resistance accept the position of P11. These results suggest that for the box type accommodation reduction of the air resistance by using interaction effects between a hull and an accommodation may be difficult to achieve.

Table 3. Effect of Position of Accommodation on Air Resistance Acting on Ships

\begin{tabular}{ccccc}
\hline No & $\begin{array}{c}\text { Air resistance } \\
(\mathbf{N})\end{array}$ & $\begin{array}{c}\text { Difference from P1, } \\
\text { \% }\end{array}$ & $\mathbf{C}_{\mathbf{d}}$ & $\begin{array}{c}\text { Difference from P1, } \\
\mathbf{\%}\end{array}$ \\
\hline P1 & 4.794 & 0 & 0.736 & 0 \\
P2 & 4.372 & -9 & 0.672 & -9 \\
P3 & 4.041 & -16 & 0.621 & -16 \\
P4 & 4.027 & -16 & 0.619 & -16 \\
P5 & 4.043 & -16 & 0.621 & -16 \\
P6 & 4.089 & -15 & 0.628 & -15 \\
P7 & 4.103 & -14 & 0.630 & -14 \\
P8 & 4.034 & -16 & 0.620 & -16 \\
P9 & 3.900 & -19 & 0.599 & -19 \\
P10 & 3.745 & -22 & 0.575 & -22 \\
P11 & 3.664 & -24 & 0.563 & -24 \\
\hline
\end{tabular}


Table 4. Interaction Effects Between Accommodation and Hull on Air Resistance

\begin{tabular}{cccccc}
\hline No & \multicolumn{2}{c}{$\begin{array}{c}\text { Independent Hull and } \\
\text { Accommodation }\end{array}$} & \multicolumn{2}{c}{$\begin{array}{c}\text { Ship Hull with } \\
\text { Accommodation }\end{array}$} & $\begin{array}{c}\text { Interaction } \\
\text { effect, \% }\end{array}$ \\
\cline { 2 - 4 } & Hull & AcC & Hull & AcC & \\
P1 & 1.682 & 1.968 & 2.682 & 2.110 & +31 \\
P2 & 1.682 & 1.968 & 2.200 & 2.172 & +20 \\
P3 & 1.682 & 1.968 & 1.887 & 2.154 & +11 \\
P4 & 1.682 & 1.968 & 1.895 & 2.132 & +10 \\
P5 & 1.682 & 1.968 & 1.934 & 2.108 & +11 \\
P6 & 1.682 & 1.968 & 1.983 & 2.106 & +12 \\
P7 & 1.682 & 1.968 & 1.990 & 2.112 & +12 \\
P8 & 1.682 & 1.968 & 1.931 & 2.101 & +10 \\
P9 & 1.682 & 1.968 & 1.785 & 2.115 & +7 \\
P10 & 1.682 & 1.968 & 1.658 & 2.087 & +3 \\
P11 & 1.682 & 1.968 & 1.466 & 2.198 & 0 \\
\hline
\end{tabular}

Reducing air resistance acting on a ship by using Interaction effects between hull and accommodation

In this section, interaction effects on air resistance between a hull and an accommodation of a ship are used to reduce air resistance by the developed accommodations, M2 and streamlined accommodation as shown in Figure 4. The accommodations M1, M2 and Streamline are located at fore deck of the ship as shown in Figures 13, 14 and 15.

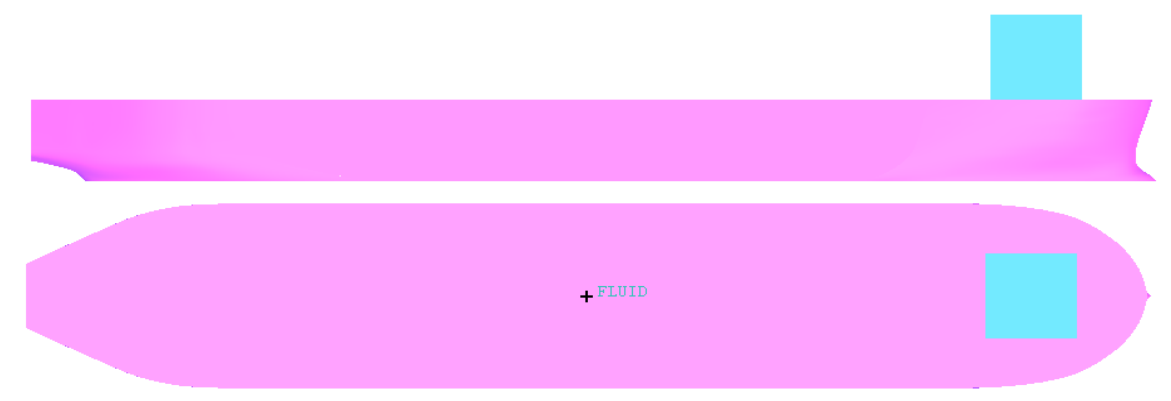

Figure 13. Ship with plating box shape accommodation M1 on the fore deck

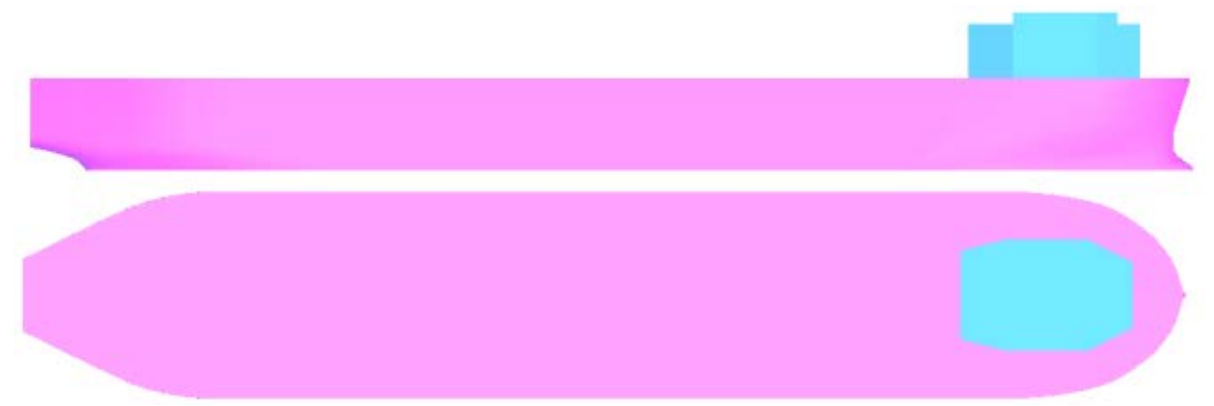

Figure 14. Ship with plating accommodation M2 on the fore deck 
Figure 15. Ship with Streamlined accommodation on the fore deck

The three models ship with the accommodation located at force are calculated air resistance acting on hull by the CFD. Figure 16 and 17 show the calculated results of air resistance acting on the ship in two cases: with and without interaction effects between a hull and an accommodation house on it deck. The detail air resistance acting on the hull and the accommodation are shown in the Tables 5 and 6.

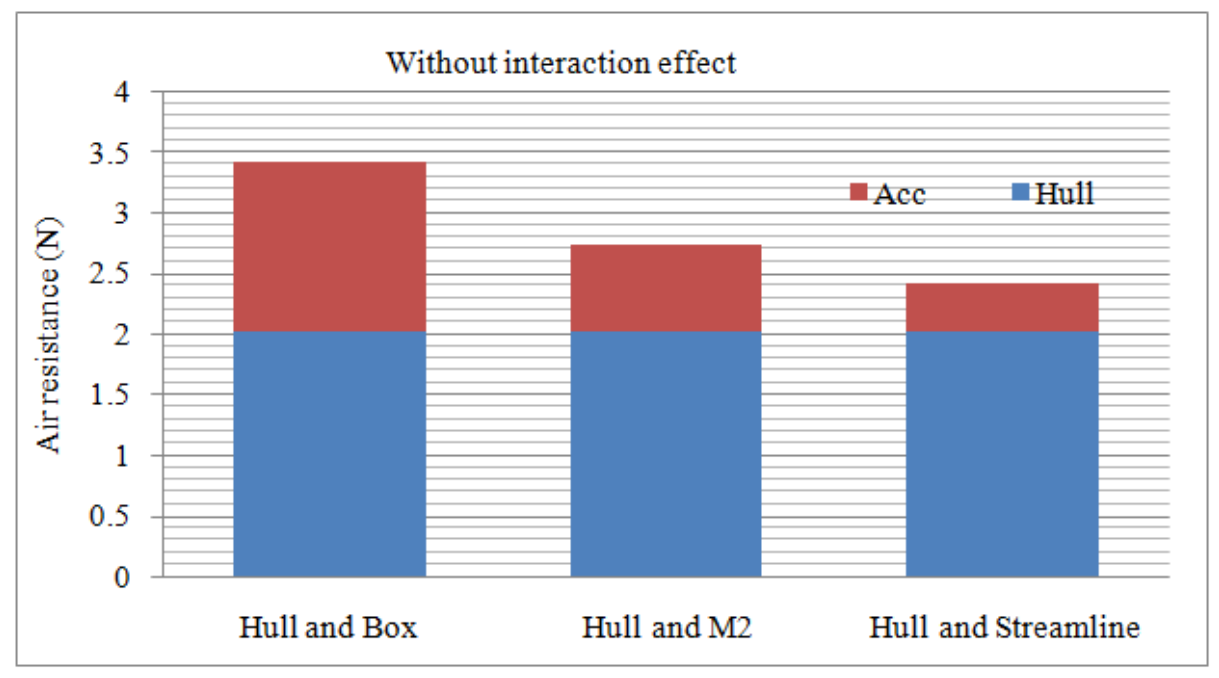

Figure 16. Computed air resistance by summing up that acting on independent hull and accommodation

Table 5. Calculated Results of Air Resistance Acting on Independent Hull and Accommodation

\section{Independent Hull and Accommodation}

$\begin{array}{llll}\text { Name } & \text { Hull and Box } & \text { Hull and M2 } & \text { Hull and Streamline }\end{array}$

$\begin{array}{cccc}\text { Hull } & 2.03 & 2.03 & 2.03 \\ \text { Acc } & 1.4 & 0.716 & 0.389\end{array}$




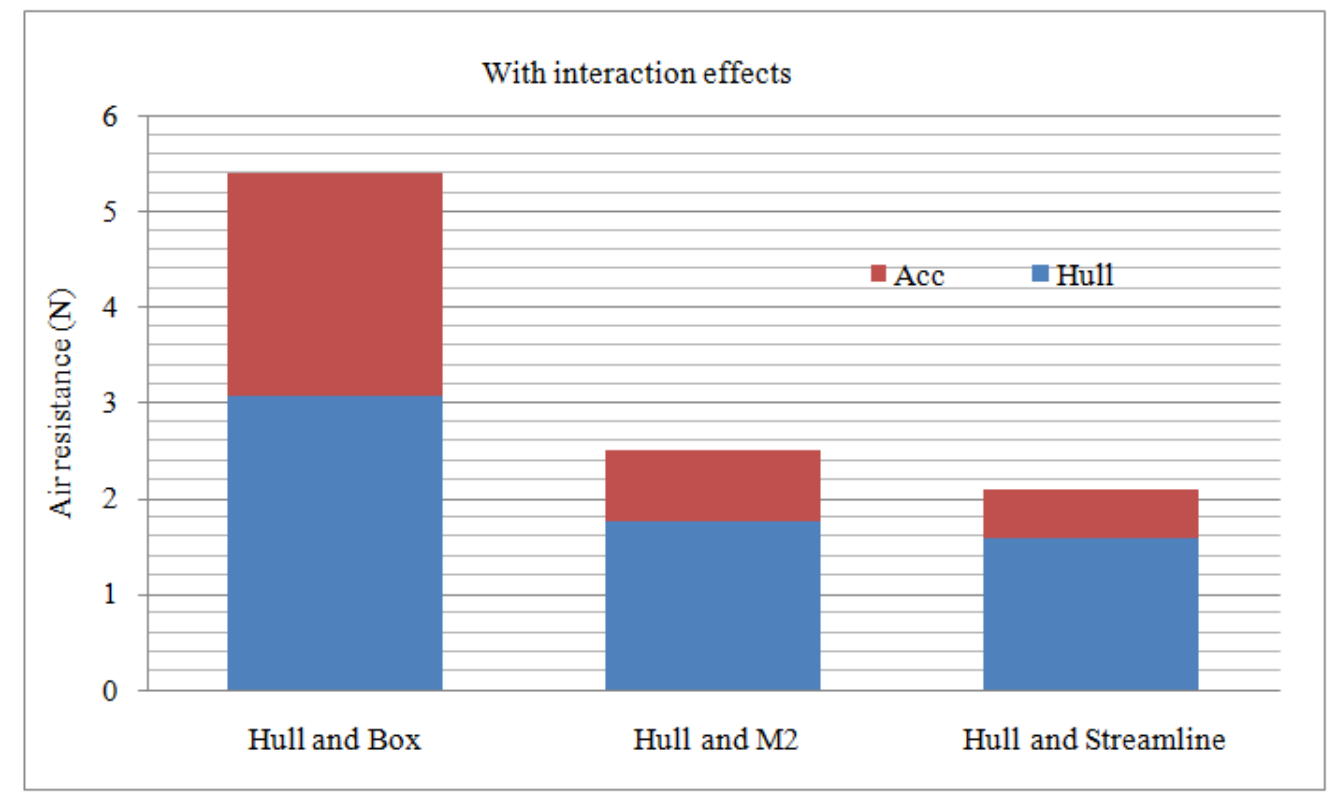

Figure 17. Calculation air resistance acting on a ship with a hull and an accommodation

Table 6. Calculated Results of Air Resistance Acting on Hull and Accommodation

\begin{tabular}{cccc}
\hline \multicolumn{4}{c}{ Hull and Accommodation } \\
\hline & Hull and Box & Hull and M2 & Hull and Streamline \\
Hull & 3.064 & 1.751 & 1.578 \\
Acc & 2.333 & 0.754 & 0.521 \\
\hline
\end{tabular}

Table 7. Interaction Effects Between Accommodation and Hull on Air Resistance

\begin{tabular}{cccccc}
\hline Name & \multicolumn{2}{c}{$\begin{array}{c}\text { Independent Hull and } \\
\text { Accommodation }\end{array}$} & \multicolumn{2}{c}{$\begin{array}{c}\text { With Hull and } \\
\text { Accommodation }\end{array}$} & $\begin{array}{c}\text { Interactio } \\
\text { n effect,\% }\end{array}$ \\
\cline { 2 - 4 } Hull and Box & Hull & Acc & Hull & Acc & \\
Hull and M2 & 2.03 & 1.4 & 3.06 & 2.33 & $36 \%$ \\
Hull and Streamline & 2.03 & 0.716 & 1.75 & 0.75 & $-10 \%$ \\
\hline
\end{tabular}

The results shown in Figs.16 and 17 shows that the air resistance can be reduced by using the interaction effects for the accommodation M2 and the streamlined accommodation which are located at force of the ship. Table 7 shows interaction effects on air resistance between hull and accommodation. It should be noted that the box shape accommodation increases the air resistances acting on the hull and accommodation by about $50-60 \%$ due to interaction effect, however M2 and the streamlined accommodations decrease the air 
resistance acting on the hull. The reason can be seen in the results of dynamic pressure distribution and flow velocity vector around ship. Figures 18 and 19 show drastically reduced separation flow after the streamlined accommodation on the deck.
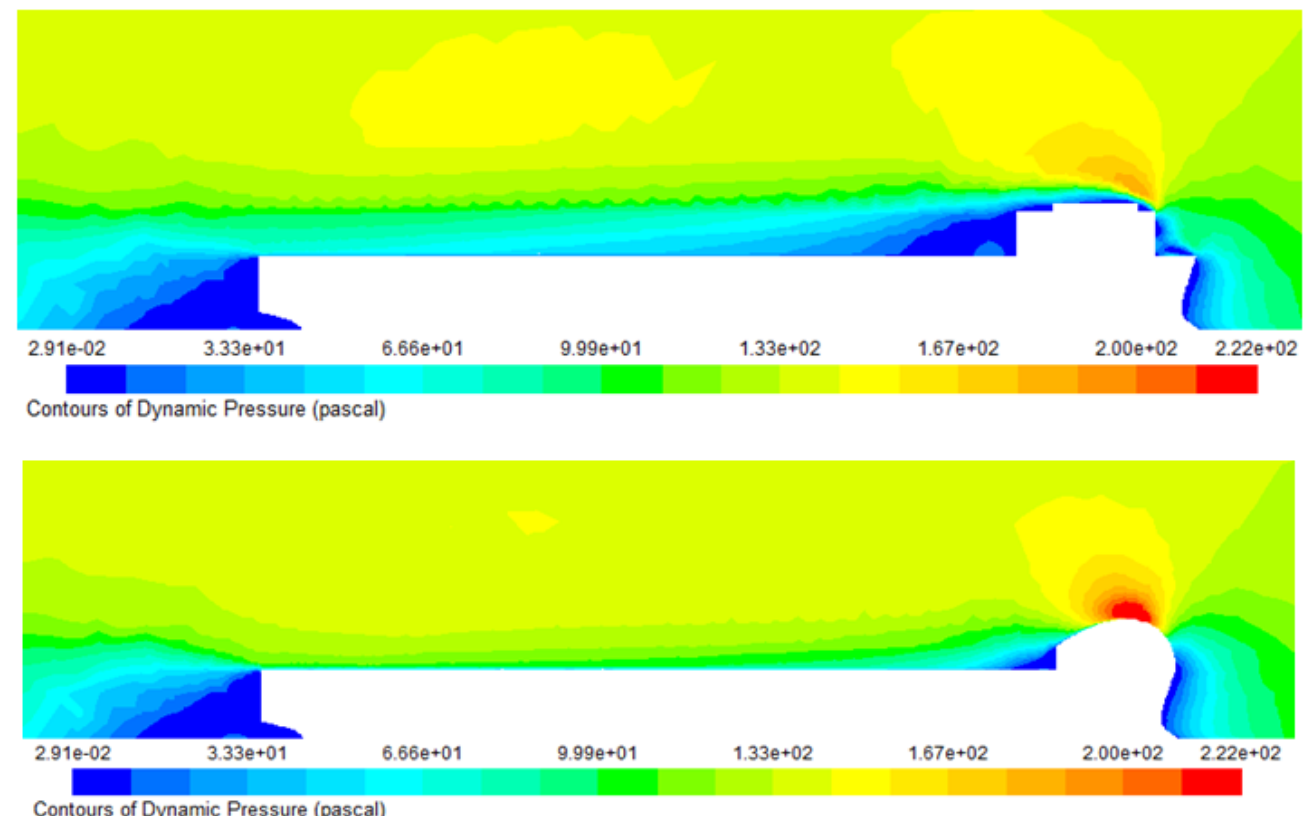

Figure 18. Dynamic pressure distribution at centre plan of calculating domain

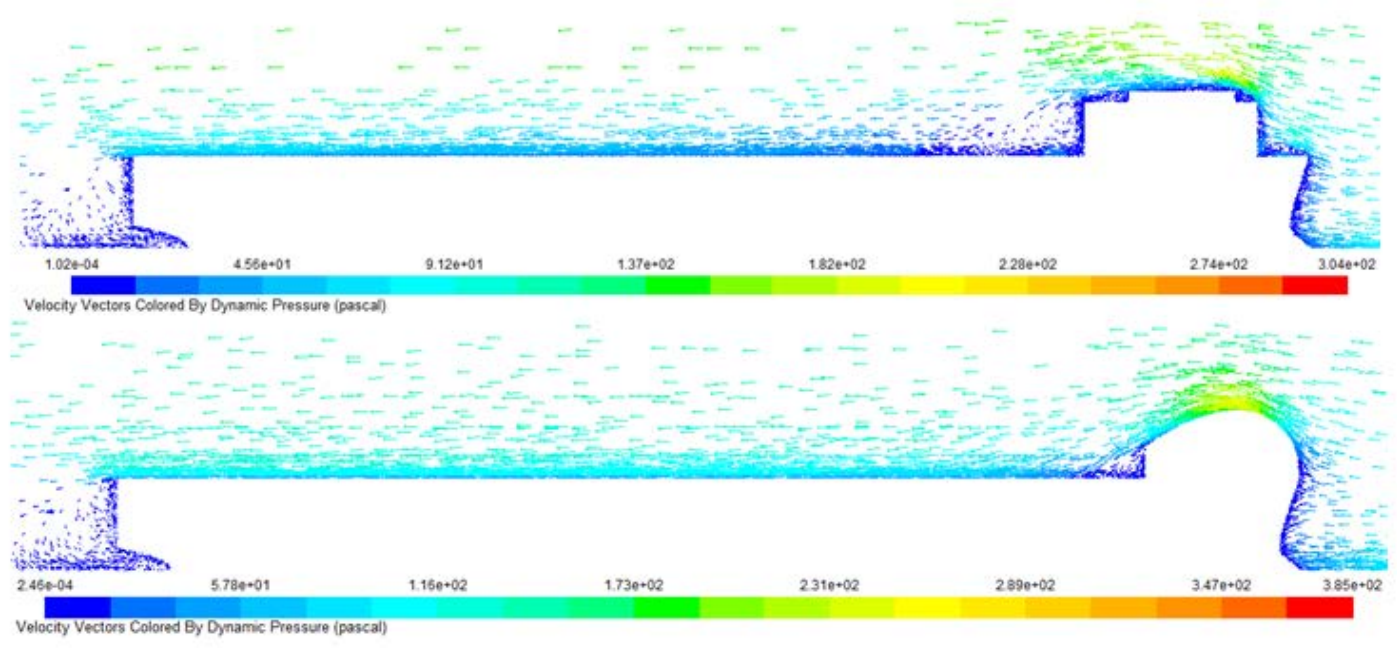

Figure 19. Velocity vectors distribution at centre plan of calculating domain

\section{Conclusions}

The paper has presented study on interaction effects of a hull and an accommodation on air resistance in detail. To find a method to reduce air resistance acting on a ship by using 
interaction effects between hull and accommodation on deck. The conclusions of this paper are summarized as follows:

- The air resistances acting on independent accommodations are calculated by CFD, and small resistance accommodations are developed.

- The CFD calculations show that location of an accommodation significantly affects the air resistance acting on a whole ship. A box-shaped accommodation located on fore deck give the smallest air resistance but no reduction of the resistance is obtained by interaction effect.

- A streamlined accommodation and a small resistance accommodation built of only flat plates located on fore decks can reduce the air resistance by using interaction effects between a hull and an accommodation.

- The reduction of the air resistance is caused by reduction air resistance acting on the hull by the interaction effects. The shape and location of an accommodation plays an important role in the reduction.

\section{References}

[1] K. Matumoto, Y. Tanaka, K. Hirota, S. Usami, and K. Takagishi, "Reduction of wind force acting on ships,” Journal of the Kansai Society of Naval Architects, Vol. 240, pp. 115-121, 2003.

[2] Y. Nihei, T. Mizobe, T. Oura, and Y. Ikeda, "A feasibility study of a new trimaran PCC in medium speed," In: Proceedings of the $4^{\text {th }}$ Asia Pacific Workshop on Marine Hydrodynamic - APHydro2008, Taipei, Taiwan, June 16-18, pp. 17-23, 2008.

[3] T. Fujiwara, Y. Tsukada, F. Kitamura, H. Sawada, and S. Ohmatsu, "Experimental investigation and estimation on wind force for a container ship," In: Proceedings of the $19^{\text {th }}$ the International Offshore and Polar Engineering Conference, Osaka, Japan, pp. 555562, 2009.

[4] K. Sugata, Y. Iwamoto, Y. Ikeda, and Y. Nihei, "Reduction of wind force acting on nonballast ship," In: Proceedings of the $5^{\text {th }}$ Asia Pacific Workshop on Marine Hydrodynamics - APHydro2010, Osaka, Japan, pp. 1-4, 2010.

[5] K. Mizutani, D. Arai, N.V. He, and Y. Ikeda, "A study on reduction of the wind resistance acting on a wood chip carrier," In: Proceedings of the $16^{\text {th }}$ the Japan Society of Naval Architects and Ocean Engineering (JASNAOE), Hiroshima, Japan, pp.285-288, 2013.

[6] N.V. He, and Y. Ikeda, "A study on interaction effects between hull and accommodation on air resistance of a ship," In: Proceedings of the $16^{\text {th }}$ the Japan Society of Naval Architects and Ocean Engineering (JASNAOE), Hiroshima, Japan, pp.281-284, 2013.

[7] K. Mizutani, Y. Akiyama, N.V. He, and Y. Ikeda, "Effects of cargo handling equipment on wind resistance acting on a wood chip carrier," In: Proceedings of the $18^{\text {th }}$ the Japan Society of Naval Architects and Ocean Engineering (JASNAOE), Hiroshima, Japan, May 24-25, pp.421-425, 2014.

[8] ITTC, Practical Used Guideline for Ship CFD Application, No. 7.5-03-01-03, 2011.

[9] N.V. He, Application of CFD to optimization of hydrodynamic performances of non ballast ships. Thesis (PhD), Osaka Prefecture University, Japan, 2013. 